\title{
Resident-Led Physical Wellness Initiative Linked to Less Burnout for Emergency Physicians during COVID-19 Pandemic
}

\author{
Camila A. Calderón, MD ${ }^{*}$, Adeola A. Kosoko, MD', Salil K. Bhandari, MD', Jason A. Lesnick, MD', Derek R. \\ Herkes, MD', Ryan M. Huebinger, MD'
}

DOI: 10.18297/jwellness/vol3/iss3/1

Website: https://ir.library.louisville.edu/jwellness/

Affiliations: ${ }^{1}$ Department of Emergency Medicine, McGovern Medical School at the University of Texas Health Science Center at Houston

Recommended Citation: Calderón, Camila A.; Kosoko, Adeola A.; Bhandari, Salil K.; Lesnick, Jason A.; Herkes, Derek R.; and Huebinger, Ryan M. (2021) "Resident-Led Physical Wellness Initiative Linked to Less Burnout for Emergency Physicians during COVID-19 Pandemic," Journal of Wellness: Vol. 3 : Iss. 3, Article 1.

Received Date: July 10, 2021

Revised Date: Oct 18, 2021

Accepted Date: Nov 5, 2021

Publication Date: Nov 29, 2021

\section{(c) (i)}

\begin{abstract}
Introduction: The COVID-19 pandemic has taken a significant toll on societal, physical, and psychological health. Emergency physicians (EPs) are susceptible to burnout under ordinary circumstances and may be particularly vulnerable during the pandemic. To reduce pandemic-related burnout, we implemented a residency-led physical wellness initiative and evaluated the effect on burnout among EPs.

Methods: In the spring of 2020, we invited all resident and attending EPs in our department to participate in a four-week physical wellness initiative as part of a prospective study. After completing or opting out of this wellness initiative, EPs responded to an online survey comprised of five sections: demographics, participation, opinion on wellness initiative, opinion on the impact of COVID-19, and the Maslach Burnout Index (MBI-HSS). We stratified respondents by initiative participation, described the characteristics of each group, and then compared the perceived impact of COVID-19 and the MBI-HSS results between the two groups.
\end{abstract}

Results: Out of 110 eligible participants, 57 EPs completed the survey (51.8\%). Thirty-five respondents completed the wellness initiative. Few (37.1\%) documented their progress, though most worked with accountability partners (85.7\%). Most enrollees enjoyed participation (Likert Score 3.2-5, CI 2.9-3.5) and would participate again (3.3, CI 3.0-3.6). The reported effect of the COVID-19 pandemic on mental wellbeing was lower for participants, although this was not significant (2.1, CI 1.5-2.1 vs 2.4, CI 2.0-2.7, p=0.312). On the MBI-HSS, participants had a lower emotional exhaustion score (1.4, 95\% CI 0.9-1.8) than non-participants (2.2, 95\% CI 1.8-2.6, $\mathrm{p}=0.005)$.

Conclusion: Participation in a residency-led, physical wellness initiative was linked to lower emotional exhaustion for EPs during the COVID19 pandemic.

\section{INTRODUCTION}

Studies of the COVID-19 pandemic and prior pandemics have shown that isolation and distancing are associated with higher rates of anxiety, depression, post-traumatic stress disorder (PTSD) and anger [1-9]. Even under pre-pandemic circumstances, emergency physicians (EPs) in general are more susceptible than other physicians to burnout, an endstage manifestation of being chronically unwell or stressed [10-13]. The Accreditation Council for Graduate Medical Education (ACGME) has declared that psychological, emotional and physical well-being are critical facets in the development of resident physicians; thus all accredited residencies must address well-being in their curriculums [14]. COVID-19 has led to the introduction of new stressors that could endanger the well-being of an already high-risk physician group [10-13]. Burnout is a prevalent problem for medical trainees $[15,16]$.

${ }^{*}$ Correspondence To: Camila A. Calderón

Email: camila.a.calderon@uth.tmc.edu
In addition to mitigating mental health disorders, physical activity has been inversely associated with burnout among physicians. [17-19]. The purpose of this study was to implement a pilot, resident-led, goal-based physical wellness initiative for resident EPs and to evaluate whether this intervention was useful in promoting well-being and combating burnout.

\section{METHODS}

\section{Setting and participants}

In April 2020, we invited all EPs, both residents and faculty at one large, university-based emergency medicine (EM) residency training program to participate in a pilot four-week physical wellness initiative. The department hosts a three-year residency program with 60 residents and 50 faculty. After this initiative, we distributed a follow-up survey to both participants and non-participants.

Copyright: @ 2021 The author(s). This is an open access article distributed under the terms of the Creative Commons Attribution 4.0 International License (CC BY 4.0), which permits unrestricted use, 
This study received institutional review board approval, HSC-MS-20-0417. The survey was distributed with a letter of information and consent.

\section{Interventions}

The physical wellness initiative was created as an open-ended, participant designed achievement program that encouraged participants to pursue a goal during the stressors of the pandemic. As prior structured programs have found mixed results, we created an original, flexible program that encouraged participants to create a goal that they would enjoy pursuing [20]. Invitations to participate in the wellness initiative were distributed to all residents and faculty via email in April 2020. Participants choose a physical wellness goal; examples included reducing stress, losing weight, optimizing nutrition, and exercising. The physical wellness goal was intentionally vague to give the participant the freedom to choose a plan that was as detailed as the participant wanted, with no specific criteria to quantify the goal. They could indicate either working towards that goal alone or as part of a team (with an accountability partner(s)). Participants in accountability groups were encouraged to communicate throughout the initiative; for example by creating a group text message thread, having weekly phone meetings, or meeting in person. Mode of communication and extent of participation in the accountability group was at their discretion. Participants in the wellness initiative tracked their own progress in fitness apps, journals, excel sheets, and group text messages. At the end of this initiative, participants reflected on the experience in the form of a personal narrative. These narratives were rated at the end, with an award in form of a small gift certificate for the winner (the results of these narratives were not evaluated as part of this analysis).

At the conclusion of the four weeks, in May 2020, all residents and faculty in the department were invited to take an original online survey consisting of 40 questions and four sections: demographic intake questions, participation in the initiative, opinion questions on the initiative (Likert scale), opinion questions on the impact of COVID-19 (Likert scale), as well as the 22 question Maslach Burnout Index for Human Services, Medical Personnel, and Educators (MBI-HSS). The MBI-HSS consists of questions evaluating three domains of burnout: emotional exhaustion, depersonalization, and personal achievement. The MBI-HSS is a burnout index that has been previously validated with emergency medicine residents and attending physicians $[13,16,21]$.

\section{Outcomes measured}

We collected demographic characteristics including age, gender, training status (resident or attending) and year of training or practice. Wellness initiative characteristics included wellness initiative participation, wellness activity, utilization of daily progress documentation, and

\section{JOURNAL}

utilization of an accountability partner or team. Wellness initiative evaluation included enjoyment of wellness initiative, helpfulness or hindrance of accountability partner, perception of wellness initiative's effect on mental health, desire to participate in the wellness initiative again and attainment of wellness initiative goal. Outcomes were Likert score for the impact of the COVID-19 pandemic on mental health as well as the composite MBI-HSS scores for each section: emotional exhaustion, depersonalization and personal accomplishment.

\section{Analysis of the outcomes}

Survey respondents were stratified into two groups: participants (those who enrolled after the recruitment email and documented their activity) and non-participants. We then described the characteristics of each group. For participants, we calculated the average Likert score for each component of the initiative evaluation. We then calculated the average Likert score for the perceived impact of COVID-19 on well-being for each group, comparing the average score for each group using a t-test. Stratifying for participation, we then calculated the average composite MBI-HSS scores. We then compared the variance of those scores for each test subsection between participants and non-participants using the Levene test, and all compared strata were found to have equal variance. Lastly, we compared the average section scores for each group using a t-test. All analyses were performed using Stata 15.1 (College Station, TX).

\section{RESULTS}

A total of 57 physicians (35 resident and 21 attending) responded to the post-intervention survey. Thirty-five respondents ( 25 resident and 10 attending) participated in the wellness initiative. Median age was similar between the groups, but the participant group had a larger number of female participants $(37.1 \% \mathrm{v} 23.8 \%)$ and a larger proportion of residents $(71.4 \% \mathrm{v}$ $47.6 \%)$ compared to the non-participant group. Fifteen $(71.4 \%)$ non-participants engaged in their own personal wellness initiative. Exercise was the most popular activity for both participants and non-participants (Figure1).

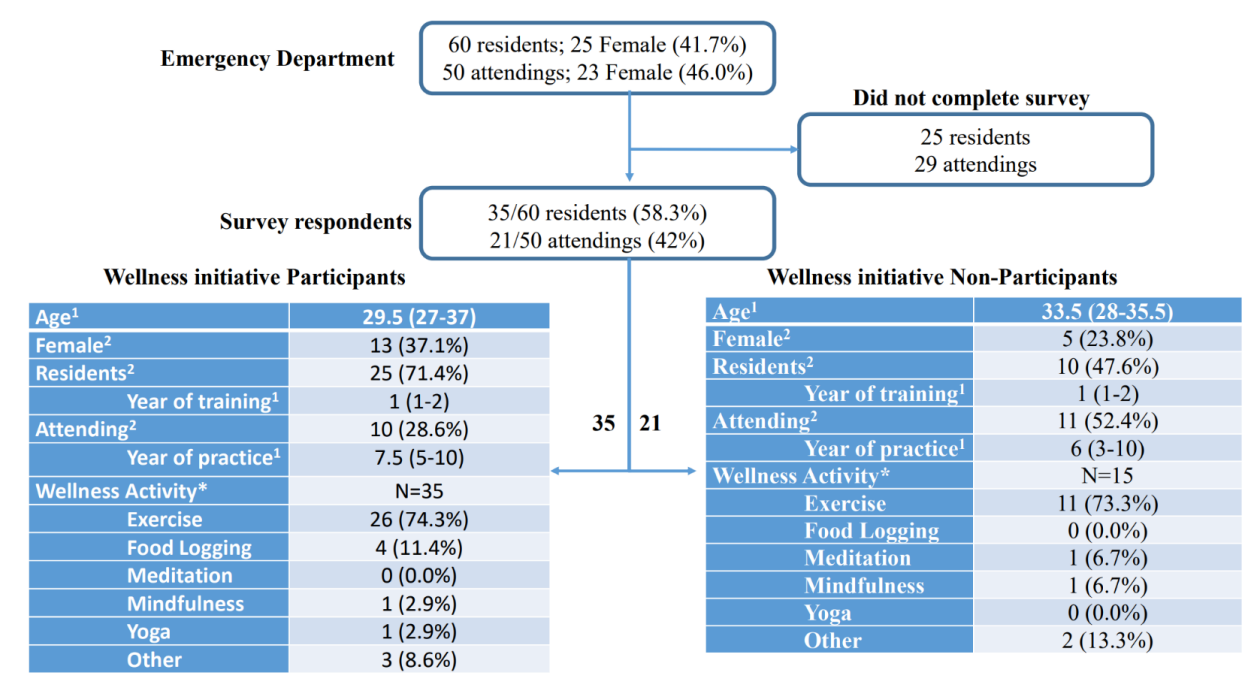

Figure 1. Characteristics of survey participants stratified by survey completion, participation in wellness initiative, and wellness initiative participation details 2 C)Wellness $2021 \mathrm{Vol} 3,(3$ 
Of enrolled wellness initiative participants, a minority (37.1\%) documented their daily progress. A large proportion utilized an accountability partner (85.7\%). Overall, participants enjoyed their participation in the wellness initiative (average Likert score 3.2, 95\% CI 2.9-3.5) and felt that they would participate in a wellness initiative again (average Likert score 3.3, 95\% CI 3.0-3.6). Participants also felt that the wellness initiative diminished the negative effects of the COVID-19 pandemic on their mental health (average Likert score 2.9. 95\% CI 2.53.2) (Table 1).

Table 1: Evaluation of wellness initiative by wellness initiative participants

$\begin{array}{lc}\begin{array}{l}\text { Evaluation of the initiative } \\ \text { Participant (N=35) }\end{array} & \begin{array}{c}\text { Average Likert score } \\ \text { I enjoyed participating in the wellness initiative }\end{array} \\ \begin{array}{l}\text { Having an accountability partner(s) made the } \\ \text { wellness initiative more effective }\end{array} & 2.2(2.9-3.5) \\ \begin{array}{l}\text { Having an accountability partner(s) was a } \\ \text { hindrance to my progress }\end{array} & 0.5(.3-0.7) \\ \begin{array}{l}\text { I would choose to participate in the wellness } \\ \text { initiative again }\end{array} & 3.3(3.0-3.6) \\ \begin{array}{l}\text { I attained the goal I set for myself at the beginning } \\ \text { of the wellness initiative }\end{array} & 2.5(2.1-2.9) \\ \begin{array}{l}\text { The wellness initiative helped my mental health } \\ \text { regarding the Covid-19 pandemic }\end{array} & 2.9(2.5-3.2) \\ \begin{array}{l}\text { Documented daily progress } \\ \text { Docume }\end{array} & 13(37.1 \%)\end{array}$

Participants in the wellness initiative felt less affected by the pandemic (average Likert score $2.195 \%$ CI 1.5-2.1) than non-participants (average Likert score 2.4, 95\% CI 2.0-2.7), though this difference was not statistically significant $(\mathrm{p}=0.3)$ (Figure 2).

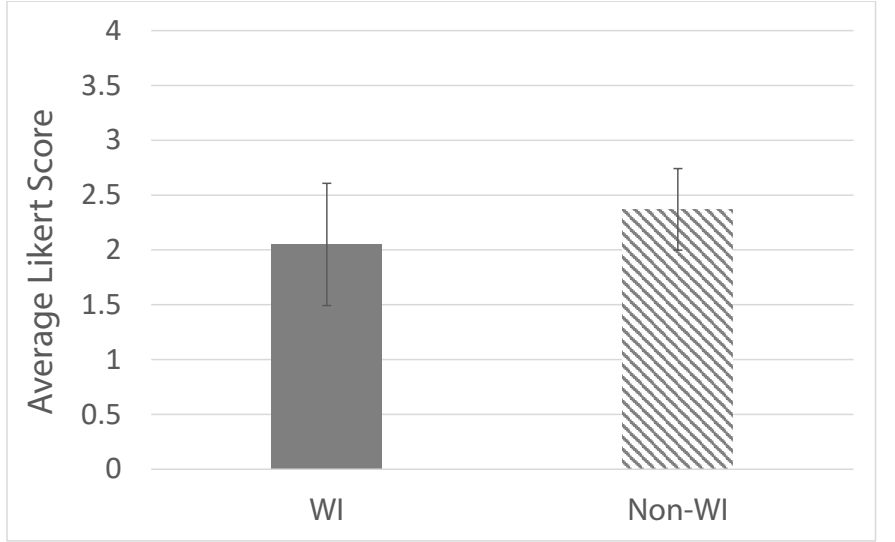

WI - participants in wellness initiative

Non-WI - non-participants in wellness initiative

Figure 1. Likert score for answer to "The Covid-19 pandemic has affected my mental health" - Stratified by participation in wellness initiative

On the MBI-HSS, overall respondent subsection mean scores for emotional exhaustion was 1.9 (95\% CI 1.6-2.2; median 1.8 IQR 1-2.7; skewness 0.5), depersonalization was 1.8 (95\% CI 1.5-2.1; median 1.6, IQR 1.2-2.2; skewness 1.2) and accomplishment was 4.2 (95\% CI, 3.9-4.5; median 4.4, IQR 3.8-5; skewness
-1.3). For emotional exhaustion, wellness initiative participants had a lower average score (1.4 out of $9,95 \%$ CI $0.9-1.8)$ than non-participants (2.2, 95\% CI 1.8-2.6, $\mathrm{p}=0.005)$. Participants had a lower score for depersonalization ( 1.2 out of $5,95 \% \mathrm{CI}$ $0.8-1.9)$ than non- participants $(1.5,95 \%$ CI 1.0-1.9), though this was not significant $(\mathrm{p}=0.09)$. Participants also had a higher score for personal achievement (4.5 out of 8, 95\% CI 3.9-5.0) compared to non-participants $(4.1,95 \%$ CI 3.7-4.4) $(\mathrm{p}=0.16)$ (Figure 3).

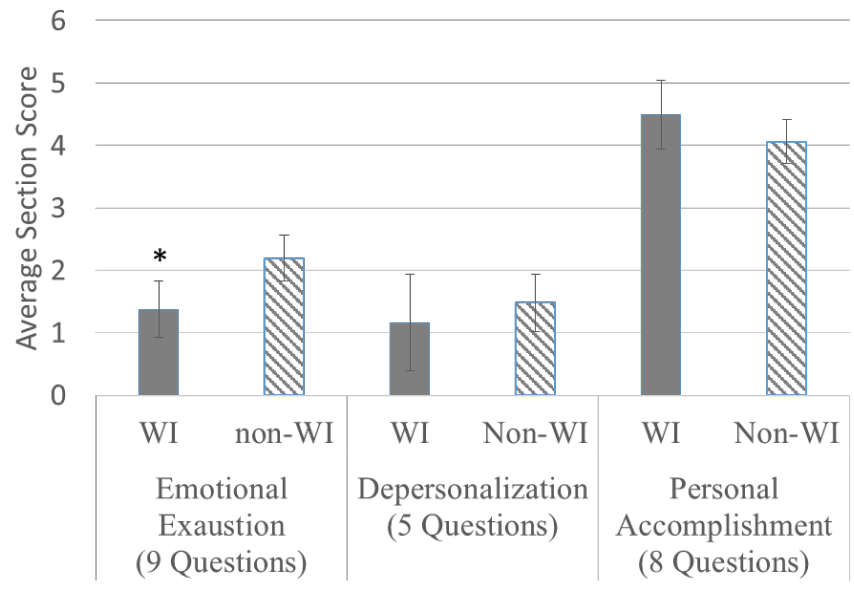

WI - participants in wellness initiative

Non-WI - non-participants in wellness initiative

Figure 3. Human Services Maslach Burnout Inventory categorical scores stratified by participation in wellness initiative

\section{DISCUSSION}

Participants in our resident-led physical wellness initiative during the COVID-19 pandemic generally enjoyed their participation and felt that they would participate in a physical wellness initiative again. We believe the flexibility of the wellness initiative gave participants the autonomy to create what best suited their wellness goals. Participants also felt that the wellness initiative helped their mental health regarding the COVID-19 pandemic. Participation in the wellness initiative was linked to significantly lower MBI-HSS scores for emotional exhaustion as well as to lower average scores for depersonalization and higher scores for personal achievement.

Resident burnout is an important problem for medical trainees, and EPs are particularly prone to burnout $[12,13,15,16$, $22,23]$. In 2017, resident wellness became an area of focus in the common program requirements by the ACGME, and many residencies across the country have since implemented wellness initiatives [14]. Additionally, other resident-led wellness initiatives have been particularly effective at improving wellness during residency $[21,24-26]$. We found participation in our initiative to be protective of emotional exhaustion.

Prior pandemics and disasters such as Hurricane Harvey, the Middle Eastern Respiratory Syndrome (MERS) pandemic, and the Severe Acute Respiratory Syndrome (SARS) pandemic have caused anxiety, depression, and PTSD in healthcare workers and patients, and initiatives to combat the negative effects of 
these stressful times are important $[1,2,4,27]$. More research is urgently needed to combat physician burnout during the COVID-19 pandemic.

While not a major focus of research, prior studies have identified the importance of physical wellness, and physicians who exercise regularly get sick less often and handle their rigorous schedules much better [30-32]. Both participants and non-participants reported exercise as the most popular activity for stress reduction. It is possible the non-participants were aware of the initiative and participated in their own wellness activities or were already practicing exercise prior to the initiative and reported exercise as a continued baseline activity. Accountability partners were frequently used by initiative participants. Accountability partner(s) and "fitness communities" promote increased physical activity and should be a focus of future physical wellness initiatives [33-35]. Interestingly, despite making up $43.6 \%$ of the department, female residents and attendings had lower participation in the wellness initiative ( 22 female versus 22 male) and lower response rates for the survey (18 female versus 38 male). Female EPs are more prone to burnout and female physicians have been found to have a lower participation and response rates than males in prior fitness studies [28, $29,36]$. Future initiatives should aim to increase the involvement of this at-risk population $[28,29]$.

Our results provide promising insight into burnout prevention among EPs during the COVID-19 pandemic. Prospective, controlled, and multi-centered studies would more robustly evaluate the efficacy of wellness initiatives. Future studies could focus on female physician participation in physical wellness activities, promoting resident leadership of such activities, and evaluation wellness initiatives for other medical specialties.

\section{LIMITATIONS}

This study is limited due to its non-randomized nature and survey response rate. A major limitation was not surveying prior to the intervention to assess the respondents' wellness baseline. Burnout could have affected some physicians' decision to enroll in the wellness initiative in the first place, and burnout could have likewise biased the decision to complete the survey. Additionally, half of the non-participants engaged in their own wellness activities. While this might bias results, the most likely impact would be to favor the null hypothesis. Finally, participation in the wellness initiative was incentivized with an award consisting of a small gift certificate for the best narratives, which could also have influenced physicians' decision to participate. Future studies regarding similar initiatives would benefit from randomization to mitigate these biases.

\section{CONCLUSION}

Participation in an emergency medicine resident-led physical wellness initiative was linked to decreased emotional exhaustion during the COVID-19 pandemic among resident and attending physicians in a large academic department.
Acknowledgments: The authors would like to thank the McGovern Emergency Department for responding to the call of duty every day.

\section{REFERENCES}

1. Hawryluck L, Gold WL, Robinson S, Pogorski S, Galea S, Styra R. SARS control and psychological effects of quarantine, Toronto, Canada. Emerg Infect Dis. 2004 Jul;10(7):1206-12.

2. Jeong H, Yim HW, Song YJ, Ki M, Min JA, Cho J, et al. Mental health status of people isolated due to Middle East Respiratory Syndrome. Epidemiol Health. 2016 Nov;38:e2016048.

3. Lai J, Ma S, Wang Y, et al. Factors Associated With Mental Health Outcomes Among Health Care Workers Exposed to Coronavirus Disease 2019. JAMA Network Open 2020;3:e203976-e.

4. Lee SM, Kang WS, Cho AR, Kim T, Park JK. Psychological impact of the 2015 MERS outbreak on hospital workers and quarantined hemodialysis patients. Compr Psychiatry. 2018 Nov;87:123-7.

5. Leiker B, Wise K. COVID - 19 case study in emergency medicine preparedness and response: from personal protective equipment to delivery of care. Dis Mon. 2020 Sep;66(9):101060.

6. Mandrola J. [CoViD-19 and PPE: some of us will die because of the shortage]. Recenti Prog Med. 2020 Apr;111(4):183.

7. Nagesh S, Chakraborty S. Saving the frontline health workforce amidst the COVID-19 crisis: challenges and recommendations. J Glob Health. 2020 Jun;10(1):010345.

8. Park SC, Park YC. Mental Health Care Measures in Response to the 2019 Novel Coronavirus Outbreak in Korea. Psychiatry Investig. 2020 Feb;17(2):85-6.

9. Venkatesh A, Edirappuli S. Social distancing in covid19: what are the mental health implications? BMJ. 2020 Apr;369:m1379.

10. Arora M, Asha S, Chinnappa J, Diwan AD. Review article: burnout in emergency medicine physicians. Emerg Med Australas. 2013 Dec;25(6):491-5.

11. Goldberg R, Boss RW, Chan L, et al. Burnout and its correlates in emergency physicians: four years' experience with a wellness booth. Academic emergency medicine : official journal of the Society for Academic Emergency Medicine 1996;3:1156-64.

12. Lu DW, Dresden S, McCloskey C, Branzetti J, Gisondi MA. Impact of Burnout on Self-Reported Patient Care Among Emergency Physicians. West J Emerg Med. 2015 Dec;16(7):996-1001.

13. Williamson K, Lank PM, Cheema N, Hartman N, Lovell EO; Emergency Medicine Education Research Alliance (EMERA). Comparing the Maslach Burnout Inventory to Other Well-Being Instruments in Emergency Medicine Residents. J Grad Med Educ. 2018 Oct;10(5):532-6.

14. Zaver F, Battaglioli N, Denq W, Messman A, Chung A, Lin $\mathrm{M}$, et al. Identifying Gaps and Launching Resident Wellness Initiatives: The 2017 Resident 
Wellness Consensus Summit. West J Emerg Med. 2018 Mar;19(2):342-5.

15. Berg DD, Divakaran S, Stern RM, Warner LN. Fostering Meaning in Residency to Curb the Epidemic of Resident Burnout: Recommendations From Four Chief Medical Residents. Acad Med. 2019 Nov;94(11):1675-8.

16. Tawfik DS, Scheid A, Profit J, Shanafelt T, Trockel M, Adair KC, et al. Evidence Relating Health Care Provider Burnout and Quality of Care: A Systematic Review and Meta-analysis. Ann Intern Med. 2019 Oct;171(8):555-67.

17. Nizamuddin SL, Nizamuddin J, Latif U, et al. Be Active and Be Well? A Cross-sectional Survey of US Anesthesia Residents. J Educ Perioper Med 2020;22:E640-E.

18. Olson SM, Odo NU, Duran AM, Pereira AG, Mandel JH. Burnout and Physical Activity in Minnesota Internal Medicine Resident Physicians. J Grad Med Educ. 2014 Dec;6(4):669-74.

19. Weight CJ, Sellon JL, Lessard-Anderson CR, Shanafelt TD, Olsen KD, Laskowski ER. Physical activity, quality of life, and burnout among physician trainees: the effect of a team-based, incentivized exercise program. Mayo Clin Proc. 2013 Dec;88(12):1435-42.

20. Parsons M, Bailitz J, Chung AS, Mannix A, Battaglioli $\mathrm{N}$, Clinton $\mathrm{M}$, et al. Evidence-Based Interventions that Promote Resident Wellness from the Council of Emergency Residency Directors. West J Emerg Med. 2020 Feb;21(2):412-22.

21. Trockel M, Bohman B, Lesure E, et al. A Brief Instrument to Assess Both Burnout and Professional Fulfillment in Physicians: Reliability and Validity, Including Correlation with Self-Reported Medical Errors, in a Sample of Resident and Practicing Physicians. Academic psychiatry : the journal of the American Association of Directors of Psychiatric Residency Training and the Association for Academic Psychiatry 2018;42:11-24.

22. Stehman CR, Testo Z, Gershaw RS, Kellogg AR. Burnout, Drop Out, Suicide: Physician Loss in Emergency Medicine, Part I. West J Emerg Med. 2019 May;20(3):485-94.

23. Thomas NK. Resident burnout. JAMA. 2004 Dec;292(23):2880-9.

24. Aggarwal R, Deutsch JK, Medina J, Kothari N. Resident Wellness: An Intervention to Decrease Burnout and Increase Resiliency and Happiness. MedEdPORTAL. 2017 Nov; 13:10651.

25. Lefebvre D, Dong KA, Dance E, et al. Resident Physician Wellness Curriculum: A Study of Efficacy and
Satisfaction. Cureus 2019;11:e5314-e. https://doi. org/10.7759/cureus.5314.

26. Runyan C, Savageau JA, Potts S, Weinreb L. Impact of a family medicine resident wellness curriculum: a feasibility study. Med Educ Online. 2016 Jun;21(1):30648.

27. Yeo CJ, Román GC, Kusnerik D, Burt T, Mersinger D, Thomas S, et al. Trainee Responses to Hurricane Harvey: Correlating Volunteerism With Burnout. Front Public Health. 2018 Aug;6:224.

28. Soltanifar A, Pishbin E, Attaran Mashhadi N, Najaf Najafi M, Siahtir M. Burnout among female emergency medicine physicians: A nationwide study. Emerg Med Australas. 2018 Aug;30(4):517-22.

29. Perrin DL, Cordingley DM, Leiter JR, MacDonald PB. Physical fitness of medical residents: Is the health of surgical residents at risk? Canadian journal of surgery Journal canadien de chirurgie 2018;61:345-9.

30. Derman PB, Liu J, McLawhorn AS. 24-Hour Fitness: the Orthopedic Resident On-Call Workout. HSS J. 2015 Oct;11(3):294-8.

31. Josephson EB, Caputo ND, Pedraza S, Reynolds T, Sharifi $\mathrm{R}$, Waseem $\mathrm{M}$, et al. A sedentary job? Measuring the physical activity of emergency medicine residents. J Emerg Med. 2013 Jan;44(1):204-8.

32. Williams AS, Williams CD, Cronk NJ, Kruse RL, Ringdahl EN, Koopman RJ. Understanding the exercise habits of residents and attending physicians: a mixed methodology study. Fam Med. 2015 Feb;47(2):118-23.

33. Carter A, Alexander AC. A Qualitative Exploration of Womens' Experiences Who Belong to a "Fitness Community”. Am J Health Educ. 2020;51(1):22-30.

34. Wallace JP, Raglin JS, Jastremski CA. Twelve month adherence of adults who joined a fitness program with a spouse vs without a spouse. J Sports Med Phys Fitness. 1995 Sep;35(3):206-13.

35. Nutting R, Grant JT, Ofei-Dodoo S, Runde MS, Staab KA, Richard BR. Increasing Resident Physician Well-Being through a Motivational Fitness Curriculum: A Pilot Study. Kans J Med. 2020 Sep;13:228-34.

36. Daneshvar F, Weinreich M, Daneshvar D, Sperling M, Salmane C, Yacoub H, et al. Cardiorespiratory Fitness in Internal Medicine Residents: Are Future Physicians Becoming Deconditioned? J Grad Med Educ. 2017 Feb;9(1):97-101. 